\title{
CLIMATE CHANGE IMPACT AND RESPONSE OF RICE YIELD
}

\author{
Mamta Rana*, K.K. Singh ${ }^{1}$, Nisha Kumari, J. Sanjay ${ }^{2}$, Ganesh Borpatra Gohain ${ }^{1}$, Naveen Kalra ${ }^{3}$ \\ *Centre of Excellence for Energy and Environmental Studies (CEEES), Deenbandhu Chhotu Ram University of Science \& \\ Technology, Murthal, (Sonepat), Haryana - 131039, India: mrana.geo@ gmail.com \\ ${ }^{1}$ Agromet Advisory Services Division, India Meteorological Department, Lodi Road, New Delhi, -110003, India \\ ${ }^{2}$ Indian Institute of Tropical Meteorology, Ministry of Earth Sciences, Pune-411008, India \\ ${ }^{3}$ Agricultural Physics, Indian Agricultural Research Institute, New Delhi-110 01, India.
}

Commission III, WG III/10

KEY WORDS: Climate Change, Kharif Rice Yield, Phenophases, Rainfall, Crop Simulation Model

\begin{abstract}
Rice is an important cereal crop and part of daily diet not only in India but also throughout Asia. Agriculture is highly dependent on the variations in temperature, precipitation and solar radiation and long-term climate patterns. The pattern of changing climate in last 30 years indicate that predictable and possible changes in rainfall and temperature can reduce agriculture outputs and yields particularly for rice and wheat significantly. The main aim of this research paper is to study the Kharif Rice Productivity in Hisar, Haryana under changing climate. The study focuses on the impacts of climate change namely intensity, timings and spatial distribution of rainfall. Kharif rice is more vulnerable to meteorological drought due to growing uncertainties in monsoon rains under the changing climate patterns. The study of seasonal changes in precipitation at decadal scale for observed and CORDEX projected precipitation for the selected region was done to understand the impacts of climate change. Along with this, DSSAT Crop Simulation Model was run to quantify the water stress in the years with more negative rainfall departure and to identify the reasons for variability in yield. DSSAT model was able to simulate phenological events and final grain yield at maturity stage with reasonable accuracy under varied weather conditions. The analysis of the simulated results indicates the association between yield and rainfall amount and its distribution during the season and different phenological growth stages of rice. The results further indicate that water stress at important stages such as Booting, Heading and Flowering majorly impact the final yield.
\end{abstract}

\section{Introduction}

Climate Change is a global phenomenon and an important global issue. Global/Regional Circulation models predict that in central Asia temperatures are likely to increase by 3-4 deg C and the atmospheric $\mathrm{CO}_{2}$ concentration will increase to 485 $1000 \mathrm{ppm}$. The increased $\mathrm{CO}_{2}$ concentration from present $380 \mathrm{ppm}$ will have positive physiological effects still yield are likely to decrease by $30 \%$ due to increasing temperature predictions. (Devkota et al., 2013).

Rice is grown under varying climate conditions and altitudes in India. Therefore, rice-growing season vary across the entire country, depending upon temperature, monsoon, soil types, water availability and other weather conditions prevail in the particular region. Kharif is the main rice-growing season in the country and sowing time for kharif rice is June-July and harvested in October-November. Haryana is northern region of the country and experiences low winter temperature and rice is grown under irrigated condition during Kharif season from May-July to September-November. Rice-Wheat crop Rotation is the dominant cropping pattern in the Haryana. (http://sap.ipni.net/article/haryana)
To quantify the effects of climate variability and developing the mitigating measures, crop simulation models can be used for studying the climate change effects and exploring the options for coping with the day-to-day variability in weather parameters and long-term changes in climate. Thus the present work is carried out to study the long-term effects of climate change on Kharif rice in Hisar, Haryana using the DSSAT 4.6v (Decision Support System for Agro technology Transfer).

Location: The study was carried out in Hisar district of the Haryana, India. Hisar is the west central most district of Haryana State and lies between the North latitudes $28^{\circ} 56^{\prime} 00^{\prime \prime}$ : $29^{\circ} 38^{\prime} 30^{\prime \prime}$ and East longitudes $75^{\circ} 21^{\prime} 12^{\prime \prime}: 76^{\circ} 18^{\prime} 12^{\prime \prime}$. It has tropical monsoonal climate and is characterized as arid type of climate. The main characteristics of climate in the district are its dryness, extremes of temperature and scanty rainfall.

*Corresponding Author: mrana.geo@gmail.com 


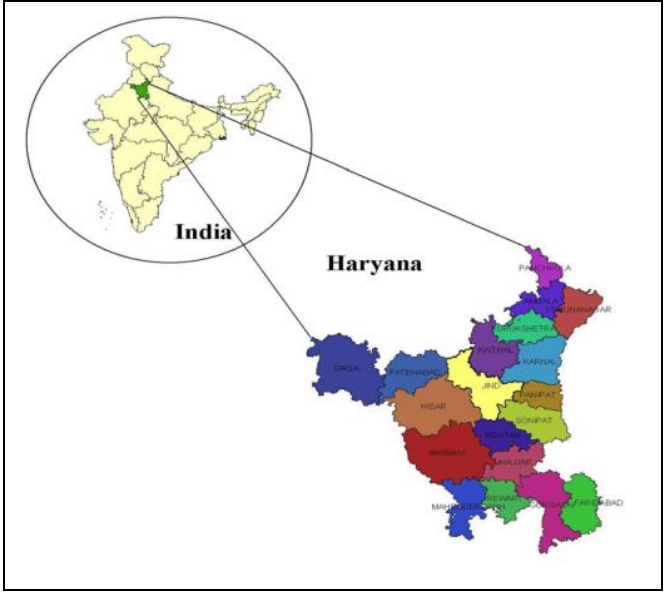

Figure 1: Location of Study Area

\section{Materials and Methods}

Model Inputs Data : DSSAT model require the daily weather data namely maximum temperature, minimum temperature, bright sunshine hours and rainfall, soil characteristics and field management practices along with selected cultivar genetic coefficients as the minimum input for simulating the yield under present and future climate conditions. The daily meteorological data was taken from India Meteorological Department, New Delhi and required field management and soil data was collected from the Agrometeorological Department, CCSHAU, and Hisar under the FASAL scheme.
The major characteristics of the selected rice cultivar for this study are:

\begin{tabular}{|c|c|}
\hline & IR 64 \\
\hline Type of Cultivar & National \\
\hline Days to Maturity & 117 \\
\hline Plant height (cm) & 100 \\
\hline Suitable sowing time & Medium and Mid Early variety \\
\hline
\end{tabular}

Figure 2: Characteristics of Selected Cultivar

For futuristic climate, two representative concentration pathways (RCP) with moderate (RCP 4.5) and highest (RCP 8.5) greenhouse gas emissions along with baseline were used for the study. The CORDEX projections for temperature (maximum and minimum), rainfall and bright sunshine hours were used in the model as futuristic data. The output from the replications was averaged for further analysis. The assessed

Downscaled historical and future projections of climate change until the end of $21^{\text {st }}$ Century belong to the driving model CNRM-CEREFACS-CNRM-CM5 of IITMRegCM4 simulations forcing under the framework of CORDEX South Asia Experiment were obtained for simulating the yield in future and studying the impact of climate change on simulated yield.

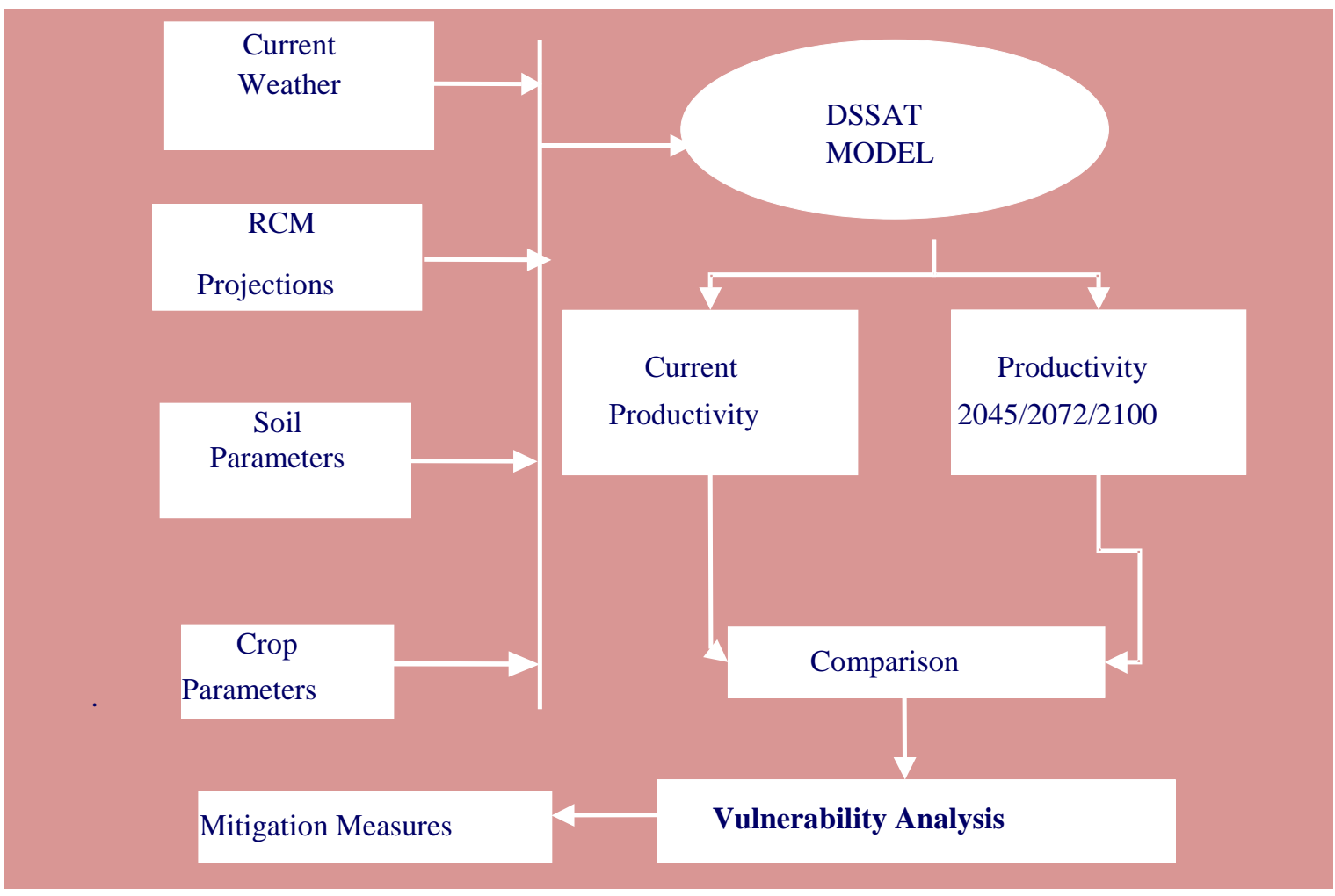

Figure 3: Schematic diagram of methodology applied 


\section{Results and Discussion}

In India, south-west monsoon is considered as the most important rainfall phenomenon affecting crop production. The contribution of SW monsoon is about $80-90 \%$ of total annual rainfall in most part of the country. Therefore, irregularities in south-west monsoon do result in moderate to severe droughts in rice growing areas. Another interesting feature of this season was the absence of an all India break monsoon condition. Break monsoon are periods of dry spell after days of continuous rainfall. It is generally supposed that the variation in the amount and temporal distribution of rainfall during growing season principally caused variation in the rice yield. (Rana et al., 2016). Along with this, the growing recognition, that climate change is supposed to have mixed effects on regions; some regions will experience gains while other will have losses in crop productivity that in turn clearly reflects the local balance of effects due to changes in temperature, soil moisture, $\mathrm{CO}_{2}$ 'fertilization' and alternations in crop pest and pathogen activity. Therefore, the use of crop growth models is one way in which these effects can be studied as these models allow the complex interaction between the main environmental variable influencing the crop yield to be understood easily.

\subsection{Baseline and Projected rainfall pattern (1986- 2016)}

Hisar falls in the semi-dry to dry region with annual rainfall of approx. $800 \mathrm{~mm}$. The long-term change in observed temperature and rainfall has been calculated for each month individually, annually (January-December) and seasonally (winter: December - February; summer: March - May; Monsoon: June-September Post-monsoon: October-November). The annual and seasonal time series was prepared from the monthly values for mean maximum and minimum temperature, mean annual temperature and rainfall. The trend analysis for this zone indicates the positive trend but with the possibilities of frequent occurrence of extreme events like increase in the intensity of rainfall and lesser number of rainy days. June month result is only statistical significant with positive trend. All seasons except winter showing positive trend with statistical significance for pre-monsoon season. Future Projections for rainfall mostly showed decreasing trend for monsoon rainfall in moderate scenario (4.5) and for extreme scenario (8.5) predicted negative trend in all classified terms from 2017-2100. The positive trend was observed in midterm (2031-2050) unlike negative trend in near term (2017-2030). But at end of $21^{\text {st }}$ Century, results indicate positive trend means increase in temperature for future projections and negative trend in case of rainfall projections. (Rana et al. 2018)

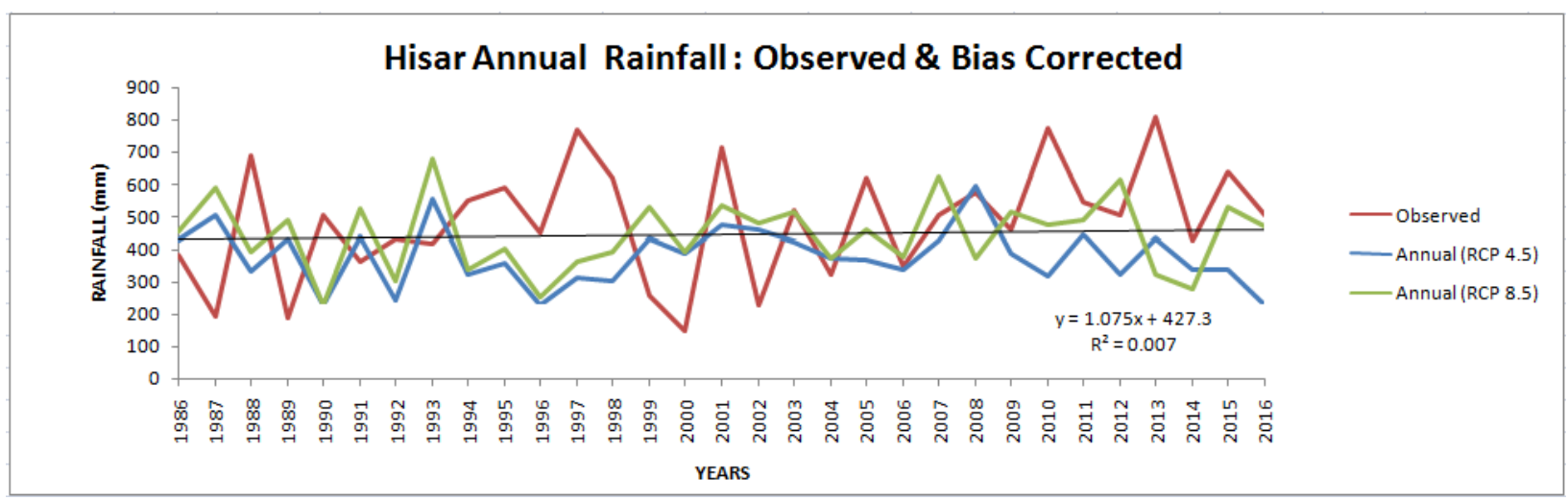

Figure 4: Annual Observed Rainfall and Variations for Baseline Period (1986-2016): HISAR

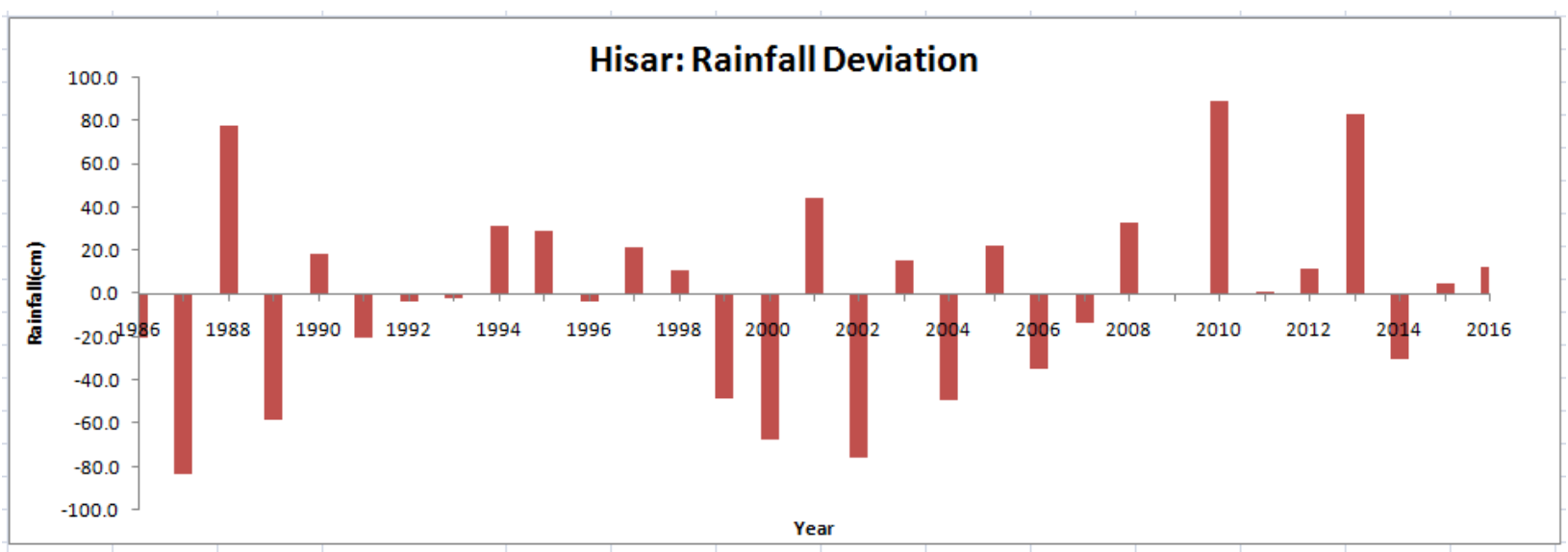

Figure 5: Rainfall Deviations from Long Period Average of Normal Rainfall for Baseline Period (1986-2016): HISAR

3.2 Simulated Rice Crop Yield for Baseline Period (1986-2016)
CERES-Rice model embedded in DSSAT was used to simulate impact of climate change on rice yield in present 
and future conditions. To achieve the desired objective a reference period (Baseline Period: 1986 - 2016) was created to examine the effects of climate change -induced changes in rice yield for the period 2017-2100.

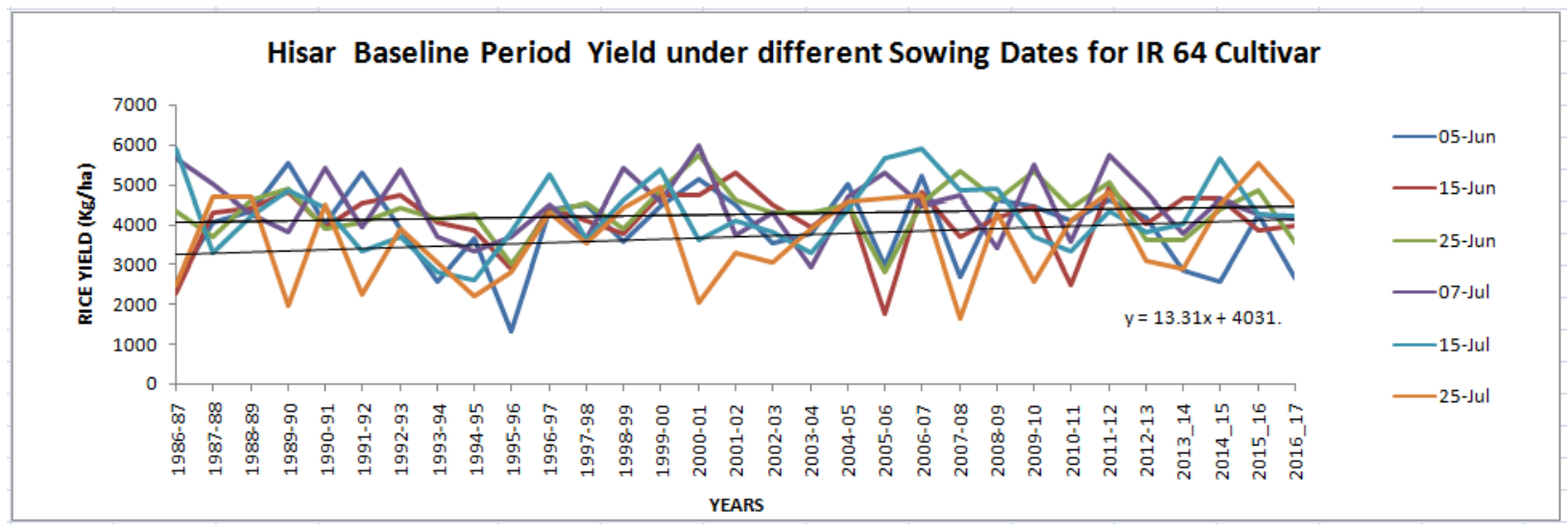

Figure 6: Simulated Rice Yield under different sowing environment for Baseline Period (1986-2016): HISAR

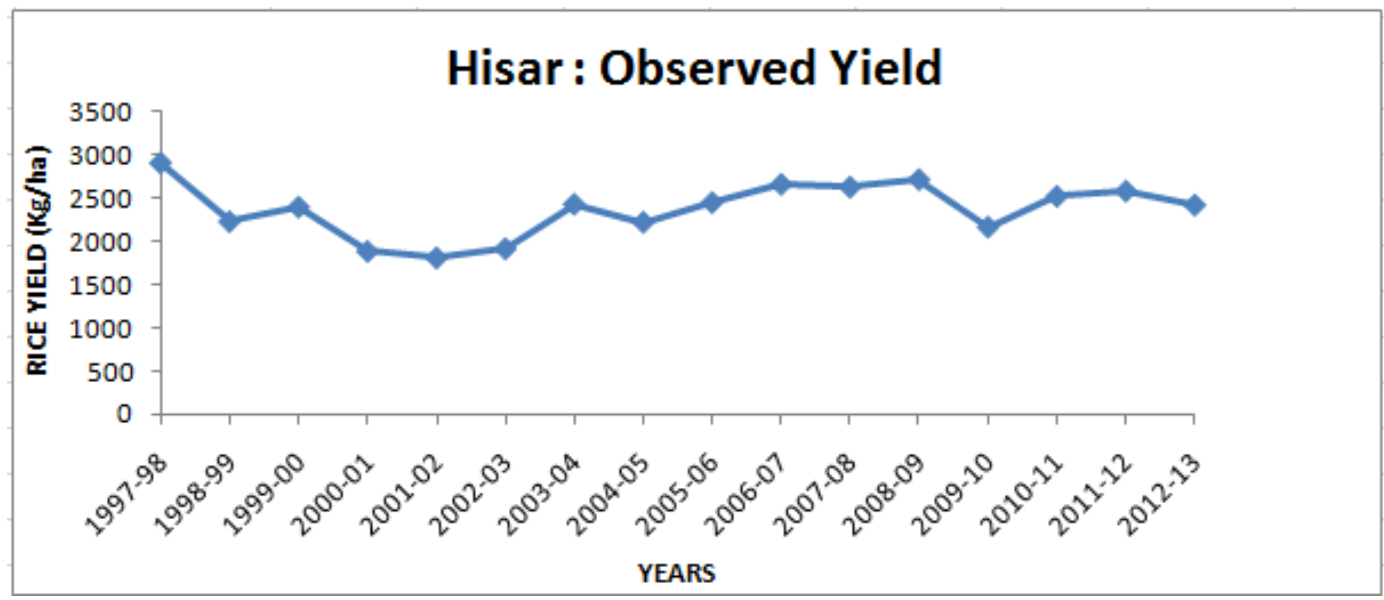

Figure 7: Rice Observed Yield for 1997-2012: HISAR

The simulated rice average yield for baseline period was $3951 \mathrm{~kg} / \mathrm{ha}$ when sown in early conditions and $3684 \mathrm{~kg} / \mathrm{ha}$ in late to very late sown conditions. The normal condition sown rice average yield was $4370 \mathrm{~kg} / \mathrm{ha}$ (Figure 6). The simulated rice yields were compared with the statistical yields from the Directorate of Economics and Statistics (DACNET), Ministry of Agriculture (Figure 7).

\subsection{Analysis of Water Availability and Important} Weather Parameters at Different Physiological Growth Stages.

To know the weather conditions and fluctuations in important weather parameters like temperature, rainfall and sunshine during different physiological stages of the rice crop, an assessment study was also carried out through CERES-rice model. The physiological growth stage wise results provides a detailed information base regarding the specific weather parameter that affect the biomass and final grain yield. The database can also help in proper irrigation scheduling and fertilizer application by looking at the results of the model that gives information about water and environment stress during various crop stages for improving productivity of the whole state. The CERES-rice model provides the following results for cultivar IR 64 under early to medium and late sowing conditions in the years, selected on the basis of maximum rainfall departure as a case study.

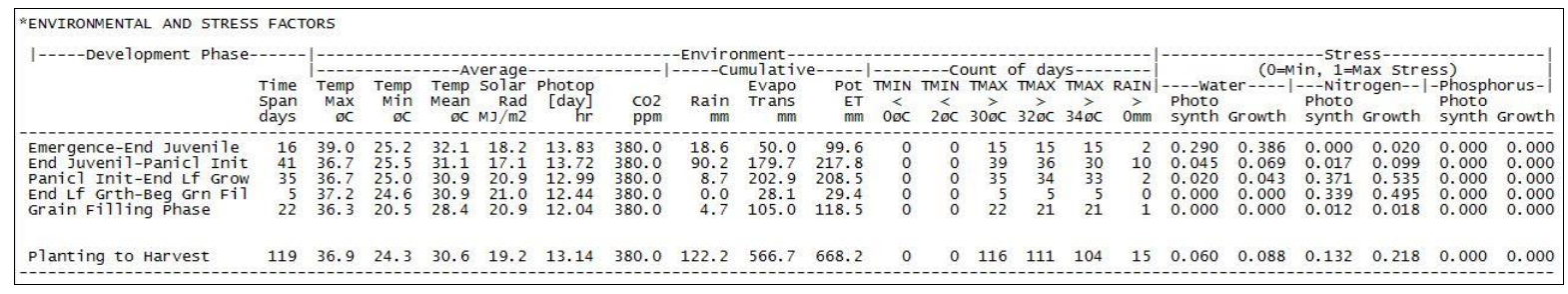

Table 5 : Distribution of important weather parameters under early to medium sowing conditions (Year:2000)) 


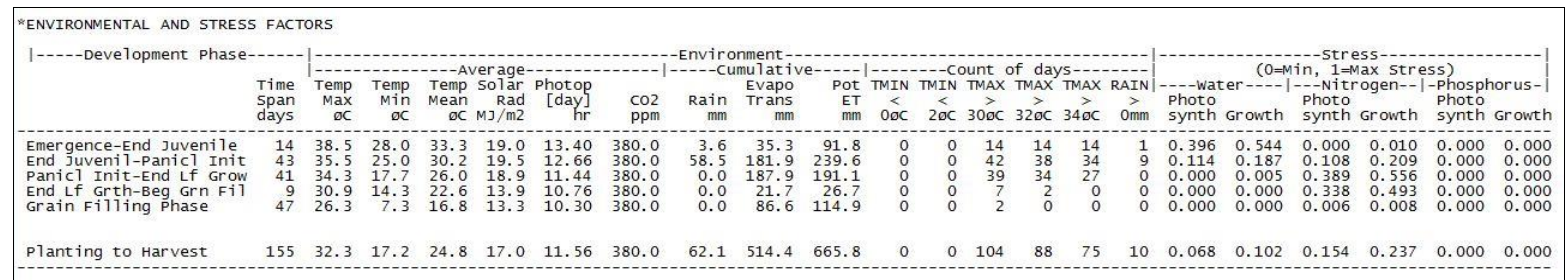

Table 6 : Distribution of important weather parameters under late to very late sowing conditions (Year:2000

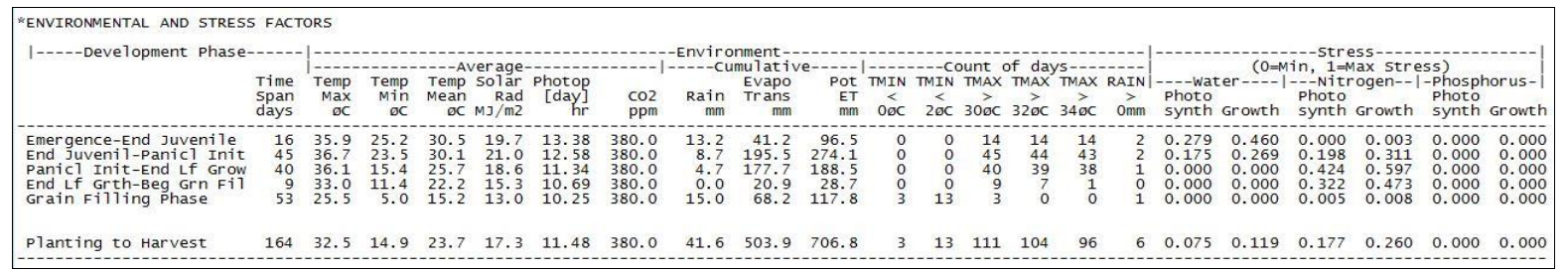

Table 7 : Distribution of important weather parameters under early to medium sowing conditions (Year:2002)

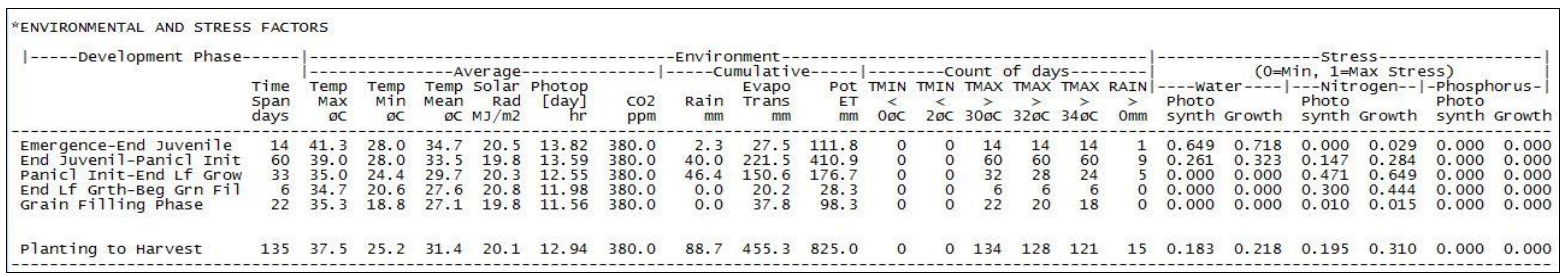

Table 8 : Distribution of important weather parameters under late to very late sowing conditions (Year:2002

The sowing time in the study area varied from $22^{\text {nd }}$ to $29^{\text {th }}$ standard meteorological week as rice is grown in Kharif season and sowing starts only after the receipt of sufficient rainfall. In the years with early or timely monsoon, the sowing starts early from $23^{\text {rd }}$ to $22^{\text {nd }}$ standard meteorological week. The low yield was observed in case of late sowing conditions as compare to early to medium sowing condition despite the normal monsoon. The table 5 to 8 shows the amount and distribution of rainfall during each physiological stage along with water and nitrogen stress. The results clearly indicate that not only the total amount of rainfall during the season but the rainfall received at critical stage also impact the final grain yield despite the irrigated conditions. The year 2002 has the more rainfall negative departure than year 2000 but the simulate yield was higher in 2002. The stage wise distribution of rainfall, with assured irrigation and less nitrogen stress could be attributed as the reason for achieving the better yield in the year with more negative departure than the other year with less rainfall departure.

\subsection{Rice Production with different planting dates under future climate change scenarios at Hisar:}

The rice yield was simulated for moderate (RCP 4.5) and extreme (RCP 8.5) scenarios from 2017-2100 to understand the the impact of climate change. The model simulated rice yield for three simulation period for RCP 4.5 scenario and two simulation period for RCP 8.5 scenario. The first simulation period of 28 years (2017-2044) was centered on year 2030, second simulation period (2045-2072) centered on year 2045 and third simulation period (2073-2100) centered on year 2085. The simulated rice yield under futuristic scenarios for first simulation period was 3293 $\mathrm{kg} / \mathrm{ha}$ in case of early sowing condition and $4552 \mathrm{~kg} / \mathrm{ha}$ in case of late sowing condition. Overall, there was slight decrease in the amount of yield for cultivar IR 64 in early sowing conditions whereas medium to late sowing condition shows increase in average yield as compare to baseline period that could be attributed to carbon fertilization effect of the increased $\mathrm{CO}_{2}$ level as simulation was run with the carbon concentration as per the present climate only i.e. $380 \mathrm{ppm}$. The early sowing of IR 64 cultivar showing decrease in average rice yield can be liked to increase in temperature that offset the positive response of increased level of $\mathrm{CO}_{2}$, therefore it can be concluded that the effect of climate change can have both positive and negative impact on crop productivity depending on the magnitude of change in temperature, rainfall and $\mathrm{CO}_{2}$ (Asaminew, 2017).

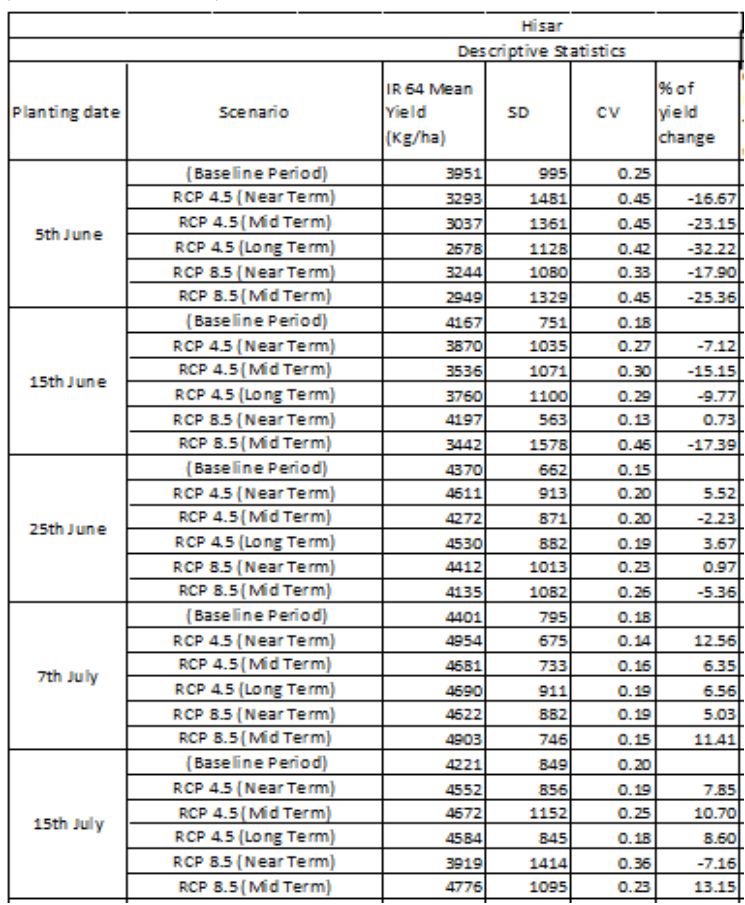

Table 9: Statistical summary of simulated rice yield under future scenarios with different sowing dates 


\section{CONCLUSIONS}

This research provided brief details about the possible impact of climate change on rice crop productivity in current and future scenarios. The results from observations and analyses of weekly, seasonal and annual rainfall alongwith crop growth simulation model suggest the variation in final yield. CERES- rice model simulation outputs provide a direction of changes in phonological growth stages according to the availability of nutrient, influence of weather parameters and other field management practices impact on yield. This enabled better preparedness to reduce the negative impact of influencing field practices or weather parameters by simple adaptation strategies such as change in variety to resistant varieties, altered agronomy and change in field management practices by high inputs delivery system and improving the efficiency of input and output resources.

\section{REFERENCES}

Asaminew T.G., Araya, A, Atkilt G, Solomon H (2017) Modeling the Potential Impact of Climate Change on
Cotton (Gossypium hirsutum) Production in Northeastern Semi-Arid Afar and Western Tigray Regions of Ethiopia. J Earth Sci Clim Change 8: 390. doi: 10.4172/21577617.1000390

Devkota, R.P., Maraseni, T.N., Cockfield, G. and Devkota, L.P. (2013) Indigenous Knowledge for Climate Change Induced Flood Adaptation in Nepal. The International Journal of Climate Change: Impacts and Responses, 5, pp. 35-46.

Rana, Mamta, Meenakshi, Singh K.K., Prasad D. Impact of Seasonal Rainfall Variability on Rice Yield and Disesase Incidence in Bihar State. Annals of Plant Protection Sciences.2016 September ;(2). Pp. 347-352.

Rana, Mamta, K.K. Singh and Nisha Kumari. Climate Change Assessment and Projections in Haryana.Vol. 20, Special Issue (August, 2018)

http://sap.ipni.net/article/haryana. [accessed on 4th December 2018] 